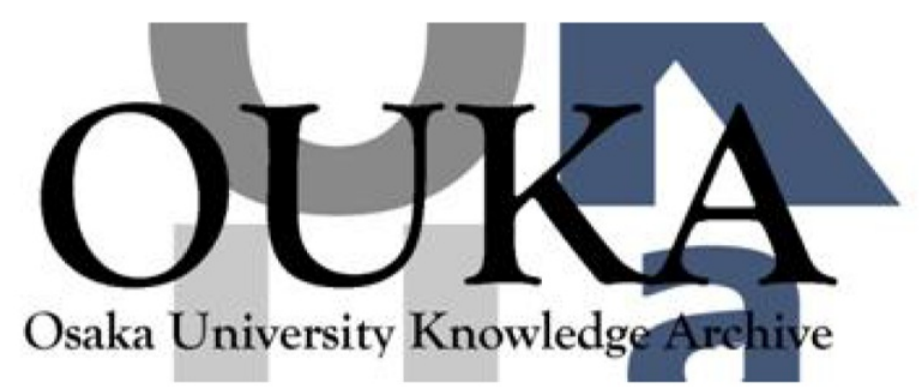

\begin{tabular}{|c|l|}
\hline Title & $\begin{array}{l}\text { Rate of Family Violence Among Patients With } \\
\text { Schizophrenia in Japan }\end{array}$ \\
\hline Author(s) & $\begin{array}{l}\text { Kageyama, Masako; Yokoyama, Keiko; } \\
\text { Nagata, Satoko et al. }\end{array}$ \\
\hline Citation & $\begin{array}{l}\text { Asia Pacific Journal of Public Health. 27(6) } \\
\text { p. 652-p. } 660\end{array}$ \\
\hline Issue Date & $2015-07-16$ \\
\hline oaire:version & AM \\
\hline URL & https://hdl. handle. net/11094/75866 \\
\hline rights & ○ 2015 APJPH \\
\hline Note & \\
\hline
\end{tabular}

Osaka University Knowledge Archive : OUKA

https://ir. Library. osaka-u. ac. jp/

Osaka University 


\section{Rate of family violence among patients with schizophrenia in Japan}

Asia-Pacific Journal of Public Health, 27(6), 652-660, 2015.

DOI: $10.1177 / 1010539515595069$

Masako Kageyama ${ }^{1}$, Keiko Yokoyama ${ }^{2}$, Satoko Nagata ${ }^{3}$, Sachiko Kita $^{4}$,

Yukako Nakamura $^{5}$, Sayaka Kobayashi ${ }^{6}$, Phyllis Solomon ${ }^{7}$

1 Department of Community Health Nursing, Graduate School of Medicine, the University of Tokyo

2 Department of Nursing, Faculty of Health Sciences, Saitama Prefectural University

3 Department of Community Health Nursing, Graduate School of Medicine, the University of Tokyo

4 Department of Midwifery and Women's Health, Graduate School of Medicine, the University of Tokyo

5 Department of Psychiatry, Nagoya University Graduate School of Medicine

6 Department of Psychiatry, Tokyo Women's Medical University

7 School of Social Policy \& Practice, University of Pennsylvania

Corresponding author

Masako Kageyama

Department of Community Health Nursing, Graduate School of Medicine, the University of Tokyo

Address: 7-3-1 Hongo, Bunkyo-ku, Tokyo 113-0033, JAPAN

E-mail: kageyama-tky@umin.ac.jp / Tel/Fax : +81-3-5841-3649 


\begin{abstract}
Family violence is a serious concern in the era of deinstitutionalization in Japan.

Consequently, we aimed to clarify the rate of family violence among patients with schizophrenia, and differences by sex and relationship to the patient. We asked households belonging to a family group association to complete a self-administered mail survey. Of 350 households that responded, data for 302 were analyzed. The rate of violence toward any family member was $60.9 \%$ over the lifetime and $27.2 \%$ in the past year. Order of lifetime rates for family members from highest to lowest was $51.0 \%$ for mothers, $47.0 \%$ for fathers, $30.7 \%$ for younger sisters, $23.8 \%$ for spouses, $19.5 \%$ for younger brothers, $18.2 \%$ for older sisters, $17.1 \%$ for older brothers, and none for children. Younger sisters were more likely to be victims compared to other siblings. Fathers and older brothers were likely to be victims when patients were male.
\end{abstract}

Keywords: family caregiving, family violence, schizophrenia, severe mental illness, siblings

\title{
Introduction
}

In 2002, the World Health Organization (WHO) issued a report on violence entitled

"World report on violence and health" to raise awareness about violence and the preventative role that public health can play ${ }^{1}$. The report discussed the following types of family violence: 
intimate partner violence, child abuse, youth violence, and elder abuse. However, family violence by persons with mental illness was not mentioned on in the report.

A modest relationship has been shown between violence and severe mental illness $(\mathrm{SMI})^{2,3,4,5}$ and violent crimes committed by patients with SMI are relatively rare events, though higher than among the general population ${ }^{6}$. However, their targets are not usually the general public ${ }^{6}$ but family members ${ }^{2,7}$. In a review, $10-40 \%$ of family members experienced violence by patients with SMI within a year or less ${ }^{8}$; however, there is little awareness about this type of violence. Family members may fear stigmatizing or inciting ill relatives.

Therefore, family violence is concealed, has not been well investigated, and is possibly more serious and pervasive than has been acknowledged.

Violence generally shows regional differences. Among WHO regions, the southeast Asia region has higher suicide rates than homicide rates with respect to deaths due to violence $^{1}$. Regarding intimate partner violence, lifetime rate of physical violence in the Asian region has been reported as 13\% in Japan, 23-34\% in Thailand, and 40-42\% in Bangladesh ${ }^{9}$, and $31 \%$ in India ${ }^{10}$. The prevalence of violence by patients with SMI is related to ethnicity ${ }^{11}$. Comparisons of family violence research among countries, to identify common and unique features, are important for effective solutions based on illness and culture. Thus, the studies need to be accumulated in the Asia-Pacific region.

Japan has a long history of having the highest psychiatric bed ratio in developed 
countries. The Japanese government created the Vision for Reform of Mental Health and Medical Welfare in 2004, to resolve unnecessarily long hospitalizations for 70,000 inpatients, and to enable their living in the community. The policy was created in the context of the social welfare structural reform by the Hashimoto cabinet from 1996. After the national policy was enacted, many policies were created and enforced in the areas of medicine, health, and welfare.

On the other hand, approximately $60-85 \%$ of patients with SMI live with their families ${ }^{12,13}$ and are supported by them daily. Living together is a factor in family violence ${ }^{14,15,16}$. In fact, of homicide cases among family members in Japan, the rate of adult perpetrators with mental illness was $17.4 \%$ in $1975-1978$, has been increasing, and reached $52.9 \%$ in $2005-2008^{17}$. Family members living with patients with SMI may be primary targets of violence in Japan. Therefore, family violence must be prevented; otherwise, we may lose family support and care for patients with SMI.

Despite this serious situation in Japan, studies regarding family violence are scarce, except for a study by Matsuyama et $\mathrm{al}^{18}$, which showed that $23.2 \%$ of parents have experienced physical violence by a patient with SMI. However, the study employed a small $(\mathrm{N}=119)$ convenience sample. Furthermore, the researchers did not analyze patients'sex or relationship to the victim, which may affect acts of family violence. As a number of studies have reported, specific diagnoses predict violence ${ }^{19}$. Schizophrenia involves a higher risk 
than other diagnoses ${ }^{20}$. Nearly all victims of homicide by patients with schizophrenia were close family members and were provoked by paranoid thoughts of the patients ${ }^{21}$. Mothers were the main targets of family violence ${ }^{14}$.

In the coming era of deinstitutionalization in Japan, violence toward family members living with individuals with SMI needs to be recognized as a serious public health concern. Moreover, a study of family violence in Japan may raise awareness in other countries in the Asian-Pacific region. To seek effective solutions, we need to first assess the rate of family violence and the relationship of the targeted family member in Japan. Therefore, in this study, we aim to clarify the rate of family violence by patients with schizophrenia and differences in rate by sex and relationship to the patient.

\section{Methods}

\section{Study Methods and Subjects}

A cross-sectional study using a mailed self-administered questionnaire was conducted.

This study was part of a larger study regarding family violence among caregivers and siblings entitled "Japanese Family Violence and Mental Illness" that aimed to clarify rates of family violence by persons with SMI. The questionnaire included not only questions regarding violence, but also factors related to violence, including psychological distress and coping strategies. This survey was conducted on all households belonging to the Saitama Prefecture Family Group Association of Persons with Mental Disorders, which is one prefectural-level 
affiliation of family groups. A total of 866 households belonged to 27 affiliate family groups of the association. Three self-administered questionnaires (two for caregivers and one for siblings) were sent to each household. The primary researcher mailed sets of questionnaires to each group leader according to the number of registered households in each group. Each group leader distributed the sets in person or sent them via mail to each household. The group leader made decisions regarding recipients and methods of distribution. An envelope with three questionnaires was distributed to one caregiver, who was asked to pass them to another caregiver and a healthy sibling. Completed questionnaires were returned directly to the primary researcher via pre-addressed envelopes. Of 866 households, group leaders distributed sets of questionnaires to 768 (422 in person and 346 via mail); 118 households were not given sets. The main reasons for not recruiting certain households were: frail elderly (42), heavy care burden (22), unknown household issue (15), potential respondents having mental disorders themselves (10), deceased patients (5), and other (24). A total of 482 caregivers from 350 households and 126 siblings returned questionnaires.

This present analysis used only questionnaires returned from caregivers and not siblings, as caregivers have the most knowledge of patients' acts of violence. If two caregivers returned surveys, we chose the one from the main caregiver. Only one questionnaire from each household was selected for the analysis. Of 350 households, data were valid for 302 households, after excluding 4 with more than half missing data, 2 missing 
data about the occurrence of violence, 36 with diagnoses other than schizophrenia, and 6

missing data about the patient's sex.

\section{Rate of Violence}

We assessed only the rate of physical violence, and did not include destruction of property and psychological violence. We operationally defined physical violence as pushing, punching, kicking, and knife threats/injuries, and asked whether violence was experienced by each family member and people outside the family for two periods (lifetime and past year). If none of these individuals existed, caregivers were asked to check "not applicable." Family members were fathers, mothers, spouses, older brothers, older sisters, younger brothers, younger sisters, and children.

\section{Data Analysis}

To understand the background of the rate of violence, we first examined the demographic data of all patients, and then compared the data by patient sex using t-tests for continuous data and chi-square tests or Fisher's exact tests for categorical data. To estimate the rate of violence, we counted the number of patients who had engaged in violence during the two periods by each family member and those outside the family. If any family member was a victim of violence by the patient, this was counted in the rates. To determine sex differences in the rate of violence, we then compared violence rates by patient sex using chi-square tests or Fisher's exact tests. All analyses were conducted using SAS Version 9.4 
(SAS Institute Inc.).

\section{Ethical Considerations}

This study was conducted with approval from the Research Ethics Committee, the Faculty of Medicine, the University of Tokyo (February 24th, 2014; No. 10415). Participants were informed of the aim of the study and that their participation was voluntary. Researchers could identify only the name of the family group, not the name of household, or the individual respondent, in order to maintain anonymity and confidentiality. Completion and return of the questionnaire was considered an indication of consent to participate. In addition, we provided agency contact information for those seeking help regarding violence.

\section{Results}

\section{Demographic Data of Patients with Schizophrenia by Sex}

Caregivers responded regarding 302 patients with schizophrenia (187 males and 115 females in 302 households). As shown in Table 1, their average age was approximately 40 years old and an average of almost 20 years had passed since the onset of schizophrenia. Over $60 \%$ had Grade 2 disability certificates, meaning that they were limited in their ability to live independently. Regarding social participation, over half had received rehabilitation or worked, whereas over $40 \%$ spent most of their time at home without the benefit of rehabilitation services. Family member respondents were on average almost 70 years old, over $80 \%$ were mothers of patients, $90 \%$ were the main caregiver, and over $80 \%$ were living 
with the patient. Demographic variables did not significantly differ based on the sex of the patient.

\section{[INSERT TABLE 1 HERE]}

\section{Rate of Family Physical Violence}

As shown in Table 2, the hierarchical order of lifetime rates of family violence was $51.0 \%$ for mothers, $47.0 \%$ for fathers, $30.7 \%$ for younger sisters, and $23.8 \%$ for spouses. The hierarchical order for past year rates were $24.3 \%$ for mothers, $16.9 \%$ for fathers, $14.3 \%$ for younger sisters, and $10.9 \%$ for spouses. Violence towards children was not indicated by responding caregivers. The rate of violence toward any family member was $60.9 \%$ (lifetime) and $27.2 \%$ (past year). The lifetime and past year rates were $8.8 \%$ and $3.4 \%$ for violence committed against people outside the family.

We compared the rates of violence by patient sex, any family members, and those outside the family. The rates of violence toward any family member in the past year and for lifetime were not significantly different by patient sex. The rates of violence toward each family member and people outside the family did not differ significantly by patient sex, except that fathers $(53.1 \%$ by male, $36.8 \%$ by female, $p=0.02)$ and older brothers in lifetime ( $22.8 \%$ by male, $4.0 \%$ by female, $p=0.04)$ were targeted more by male patients.

\section{Discussion}




\section{Rate of Family Violence}

In this study, the rates of violence toward any family member were $27.2 \%$ in the past year and $60.9 \%$ over the lifetime. The past year rate found in this study is similar in value to 23.2\% rate of Matsuyama et al. ${ }^{18}$ study, although these researchers did not define the period of occurrence. Our estimates were slightly higher than for families of community mental health services recipients in Australia (24\% in the past year and $40 \%$ lifetime) ${ }^{22}$ and a little less than for patients with schizophrenia in Canada $(31 \%$ in the past year and a little more than $52 \%$ lifetime $)^{23}$. However, these two studies had a small number of subjects $\left(101^{22}\right.$ and $61^{23}$ family members, respectively) and calculations were based on family members, rather than patients with SMI. Careful interpretation of rates reveals that the rate of family violence by patients with schizophrenia in Japan is not particularly high in the past year, but high for lifetime occurrence. This may be explained in terms of the severity of disability and long periods of cohabitation. Previous studies employed the number of hospitalizations as a measure of severity of illness ${ }^{2,16,24}$ and determined that cohabitation with patients ${ }^{14,15,16}$ were risk factors for violence. Over $60 \%$ in this study had Grade 2 disability certificates. Further, over $40 \%$ lived at home without rehabilitation services; these factors are likely indicators of a severe disability. Therefore, the patients in this study may represent those with a greater severity of illness. One reason for the long period of cohabitation in Japan is the lack of alternative residential support options which are essential for patients with severe disabilities 
to live in the community.

Moreover, the rates of violence toward any family member in the past year and for lifetime were not significantly different by patient sex, which was similar to the results of a survey conducted using family groups by Swan et $\mathrm{al}^{16}$. In the general population ${ }^{11,24}$ and among patients with schizophrenia ${ }^{24}$, males have a higher risk of violent crimes than do females. However, Robbins et $\mathrm{al}^{25}$ reported that females are more likely to target family members in the home, whereas male patients tend to target individuals outside the home. Given these findings, females with schizophrenia may have a lower risk of violent crimes outside the home than males, although both have similar risk of violent behaviors inside the home. More research is needed on this topic; however, it seems that female patients may have as high a risk of family violence as do male patients.

\section{Family Relationships and Family Violence}

Mothers were attacked slightly more often (51.0\% lifetime) than fathers (47.0\%

lifetime). These results contrast with the findings of Estroff ${ }^{14}$ who found that mothers in the US were targeted substantially more than fathers and other family members. In the present study, both fathers and mothers were primary targets of violence. Moreover, lifetime rates of violence toward fathers and older brothers were significantly higher for male patients. The mother-child connection is extraordinarily close in Japanese families ${ }^{26}$; as a result, violence is more often directed toward mothers. We assume that fathers and older brothers were trying 
to protect female family members when they became victims. Our assumption is based on two sources: comments from fathers in our study, and a real-life tragedy in 2014 in Tokyo in which a father killed his son with SMI to protect his wife and daughter ${ }^{27}$. By cross-cultural perspectives, Japanese parents have been characterized as weak fathers and dominant mothers in a period of high economic growth ${ }^{28}$. However, this study's results seem to reveal a different aspect of Japanese fathers, who lived as company soldiers, but assert themselves when presented with a life-threatening circumstance.

In this study, only younger sisters had a high rate (30\%) of being targets among siblings. Older siblings are usually respected and have considerable influence on younger siblings' development ${ }^{29}$. However, when older siblings have disabilities, healthy younger siblings take older sibling roles ${ }^{30}$. Ill older siblings may feel jealous of healthy younger siblings because they are respected by others. Younger sisters, who are generally the weakest family member, may become targets, and therefore require extra care.

\section{Violence against Others}

The rates of violence toward others were $3.4 \%$ (past year) and $8.8 \%$ (lifetime). In a study of patients with SMI by Steadman ${ }^{7}$, half of targets were family members, $35 \%$ were friends or acquaintances, and $14 \%$ were strangers. The results of the present study may reflect high rates of patients and families cohabitating and patients' severe disability grades.

\section{Implications for Public Health in Japan}


This study revealed that family members living with patients with severe

schizophrenia often face violence. This finding has the potential to promote awareness about family violence to professionals, families, and policy makers. Raising awareness is important for public health because it is a first step in the prevention of family violence and its serious consequences. Professionals such as psychiatrists and co-medical staff need to be made aware of family violence by both male and female patients with schizophrenia in order to assess for such circumstances. Special attention for young sisters is needed. Families' awareness that family violence is a common problem can promote their sharing of coping skills and collaboratively work to find solutions. A new public health policy to address this type of family violence needs to be created, in Japan to augment existing policies focused on child abuse, intimate partner violence, elder abuse, and persons with physical, intellectual, and mental disabilities. Such public health policies will promote local governments to develop services to address this issue and to formalize collaborative relationships among local government, police, and social welfare and mental health agencies. .

We also suggest services for patients with SMI and their families. First, the following additional services for patients with SMI are needed: home visitor's services, outreach crisis intervention, and alternative residential services options to promote living with professional support rather than with parents. Second, the following new services for families are also needed: teaching families such skills as de-escalation techniques, limit-setting and 
temporary crisis shelters that may help to prevent future violence against family members.

\section{Limitations and further research}

This study has several limitations. First, the representativeness of patients with schizophrenia may be of concern, because most patients who were the focus in this study had severe grade disabilities. However, the Japanese government has been promoting deinstitutionalization strategies for hospitalized patients with severe grade disabilities. Therefore, this sample is likely relatively representative of those who will be deinstitutionalized in Japan and the information is important to consider in planning for deinstitutionalization. In addition, family members in this survey were probably highly motivated to care for patients. Second, violence against others may have been underestimated. It is possible that family members were not aware of violence outside the home.

This study revealed a high rate of lifetime family violence in Japan. The prevalence of intimate partner violence in Japan is lower than in other countries. Therefore, other countries in the Asia-Pacific region may have higher rates of family violence than Japan. Studies of factors related to family violence and consequences of family violence will be helpful in prevention. Further studies about family violence by patients with SMI need to be conducted in other countries to help develop effective solutions.

\section{Conclusion}

The rate of violence toward any family member by patients with schizophrenia was 
$60.9 \%$ (lifetime) and 27.2\% (past year). The main targets were mothers, fathers, and young sisters. The rate of violence toward each family member did not differ significantly by sex, except that fathers and older brothers were targeted more by male patients. Family violence is a serious concern in the era of deinstitutionalization in Japan.

\section{Declaration of Conflicting Interests}

The author(s) declared no potential conflicts of interest with respect to the research, authorship, and/or publication of this article.

\section{Funding}

The author(s) disclosed receipt of the following financial support for the research, authorship, and/or publication of this article: The first author received financial support from the Uehiro Foundation on Ethics and Education (No. B-016, 2014-2015) for the research and publication of this article. 


\section{References}

1. Krug EG, Dahlberg LL, Mercy JA, Zwi AB, Lozano R. World Report on Violence and Health.; 2002. doi:10.1136/ip.9.1.93.

2. Arboleda-Florez J, Holley H, Crisanti A. Mental illness and violence. Int Med J. 1998;5(1):3-8. doi:10.1097/YCO.0b013e32832c08fc.

3. Choe JY, Teplin LA, Abram KM. Perpetration of Violence, Violent. 2008;59(2).

4. Modestin J. Criminal and violent behavior in schizophrenic patients: an overview. Psychiatry Clin Neurosci. 1998;52(6):547-554.

5. Walsh E, Buchanan A, Fahy T. Violence and schizophrenia: Examining the evidence. Br J Psychiatry. 2002;180(1997):490-495. doi:10.1192/bjp.180.6.490.

6. Angermeyer MC. Schizophrenia and violence. Acta Psychiatr Scand Suppl. 2000;102:63-67. doi:10.1097/00001504-199901000-00016.

7. Steadman HJ, Mulvey EP, Monahan J, et al. Violence by people discharged from acute psychiatric inpatient facilities and by others in the same neighborhoods. Arch Gen Psychiatry. 1998;55(May):393-401. doi:10.1001/archpsyc.55.5.393.

8. Solomon PL, Cavanaugh MM, Gelles RJ. Family violence among adults with severe mental illness: a neglected area of research. Trauma Violence Abuse. 2005;6(1):40-54. doi:10.1177/1524838004272464.

9. García-Moreno C, Jansen HA, Ellsberg M, Heise L, Watts C. WHO Multi-Country Study on Women's Health and Domestic Violence against Women Initial Results on Prevalence, Health Outcomes and Women's Responses Full Report.; 2005. http://whqlibdoc.who.int/publications/2005/924159358X_eng.pdf.

10. Dalal K, Lindqvist K. A National Study of the Prevalence and Correlates of Domestic Violence Among Women in India. AsiaPacific J public Heal AsiaPacific Acad Consort Public Heal. 2010. doi:10.1177/1010539510384499.

11. Corrigan PW, Watson AC. Findings from the National Comorbidity Survey on the frequency of violent behavior in individuals with psychiatric disorders. Psychiatry Res. 2005;136:153-162. doi:10.1016/j.psychres.2005.06.005. 
12. Tokyo Metropolitan Government. The Current Living Conditions of People with Disability 2013.; 2014. [in

Japanese]http://www.fukushihoken.metro.tokyo.jp/kiban/chosa_tokei/zenbun/25kekka. html.

13. Chiba Prefecture Family Association of Persons with Mental Disorders. Needs in Life and Welfare of Persons with Mental Disorders Living in the Community and Their Families 2008 - Focused on Support for Consumers in Withdrawal. [in Japanese]Chiba, Japan: Chiba Prefecture Family Association of Persons with Mental Disorders; 2009.

14. Estroff SE, Swanson JW, Lachicotte WS, Swartz M, Bolduc M. Risk reconsidered: Targets of violence in the social networks of people with serious psychiatric disorders. Soc Psychiatry Psychiatr Epidemiol. 1998;33:95-102. doi:10.1007/s001270050216.

15. Binder RL, McNeil DE. Victims and families of violent psychiatric patients. Bull Am Acad Psychiatry Law. 1986;14(2):131-139.

16. Swan RW, Lavitt M. Patterns of Adjustment to Violence in Families of the Mentally Ill. J Interpers Violence. 1988;3(1):42-54.

17. Research and Training Institute of the Minister of Justice. Research about Domestic Serious Crimes.; 2013. [in Japanese] http://www.moj.go.jp/content/000098464.pdf.

18. Matsuyama M, Morita N, Ogai Y. Mental health of parents ot the mentally disabled and its related factors: Focusing on parent abuse by the mentally disabled children. Japanese J Addict Fam. 2013;29(1):50-59. http://ci.nii.ac.jp/naid/40019604074.

19. Davis S. An overview: are mentally ill people really more dangerous? Soc Work. 1991;36(2):174-180.

20. Schanda H, Knecht G, Schreinze D, Stompe T, Ortwein-Swoboda G, Waldhoer T. Homicide and major mental disorders: A 25-year study. Acta Psychiatr Scand. 2004;110(13):98-107. doi:10.1111/j.1600-0047.2004.00305.x.

21. Gabrielsen G, Gottlieb P, Kramp P. Criminal homicide trends in Copenhagen. Stud Crime Crime Prev. 1992;1(1):106-114.

22. Vaddadi KS, Gilleard C, Fryer H. Abuse of carers by relatives with severe mental illness. Int J Soc Psychiatry. 2002;48(2):149-155. 
23. Chan BW-Y. Violence against Caregivers by Relatives with Schizophrenia. Int J Forensic Ment Health. 2008;7(January 2014):65-81.

doi:10.1080/14999013.2008.9914404.

24. Fleischman a., Werbeloff N, Yoffe R, Davidson M, Weiser M. Schizophrenia and violent crime: a population-based study. Psychol Med. 2014;44:3051-3057. doi:10.1017/S0033291714000695.

25. Robbins PC, Monahan J, Silver E. Mental Disorder, Violence, and Gender. $2003 ; 27(6)$.

26. Kumagai F. Filial Violence: A Peculiar Parent-Child Relationship in the Japanese Family Today. J Comp Fam Stud. 1981;12(3):337-349.

27. Asahi Shimbun. Decision to father who killed his third son to protect his wife and daughtor.http://www.asahi.com/articles/ASGD35DWNGD3UTIL02M.html. Published 2014.

28. Shwalb D, Imaizumi N, Nakazawa J. The modern Japanese father: Roles roles and problems in a changing society. In: Lamb M, ed. The Father's Role: Cross-Cultural Perspectives. NJ: Erlbaum: Hillsdale; 1987:247-269.

29. Cicirelli VG. Sibling Relationships in Cross-Cultural Perspective. J Marriage Fam. 1994;56(1):7-20. http://www/jstor.org/stable/352697.

30. Brody G., Stoneman Z, Davis C., Crapps J. Observations of the role relations and behavior between older children with mental retardation and their younger siblings. Am Assoc Ment Retard. 1991;95(5):527-536. 
Table 1. Demographic data of patients and responding family members

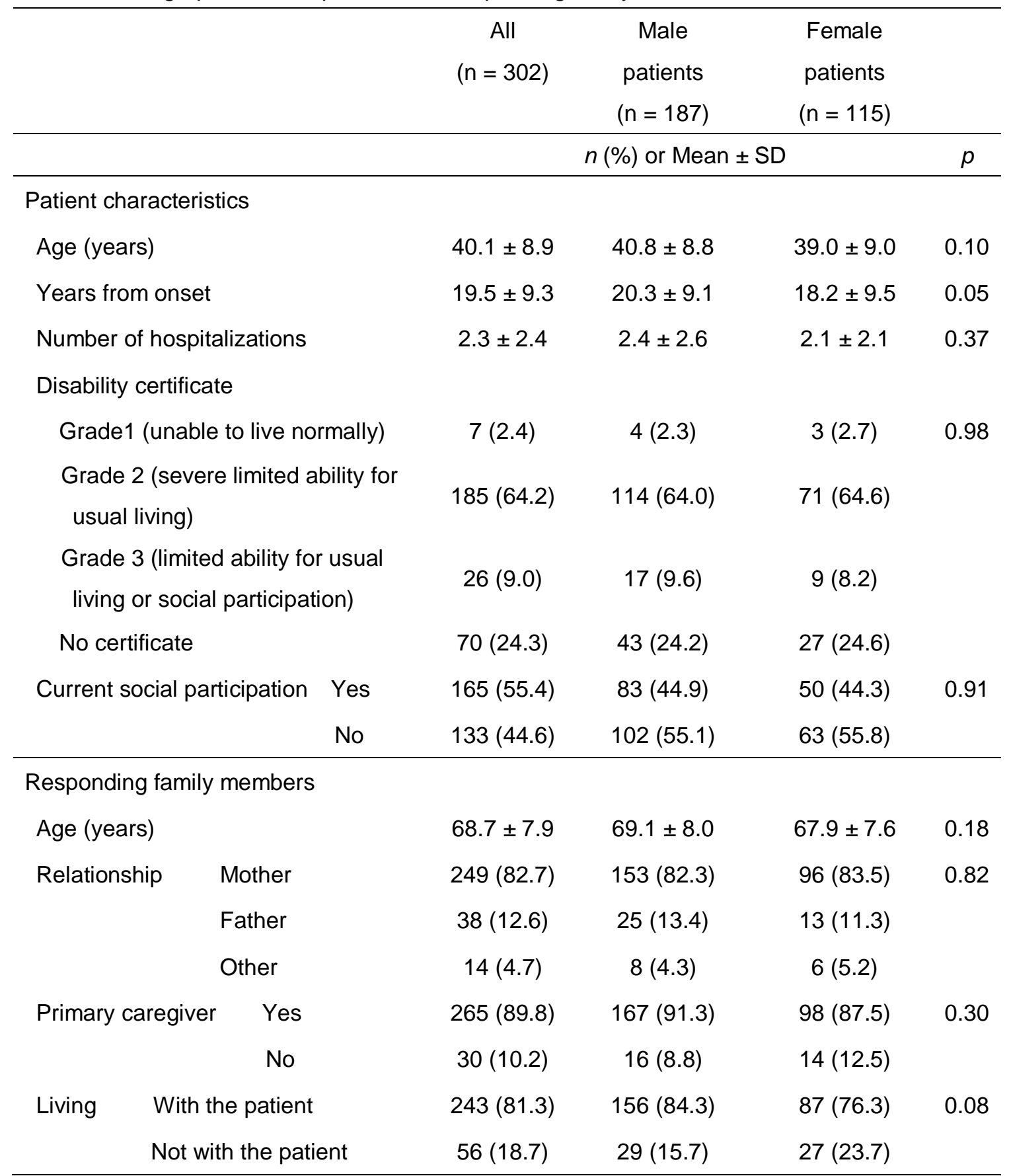

Missing data was excluded from analysis

$P$ : chi-square test, Fisher's exact test, or t-test 
Table 2. Rates of family members experiencing physical violence

\begin{tabular}{|c|c|c|c|c|c|c|}
\hline Family member & Period & & $\begin{array}{c}\text { All } \\
(n=302)\end{array}$ & $\begin{array}{c}\text { Male } \\
\text { patients } \\
(\mathrm{n}=187)\end{array}$ & $\begin{array}{l}\text { Female } \\
\text { patients } \\
(\mathrm{n}=115)\end{array}$ & $\begin{array}{c}P \\
(\text { missing, n/a) }\end{array}$ \\
\hline & & $n$ & $n(\%) n$ & $n(\%)$ & $n(\%)$ & \\
\hline \multirow[t]{2}{*}{ Father } & Lifetime & 234 & $110(47.0)$ & 78 (53.1) & 32 (36.8) & $0.02(29,39)$ \\
\hline & Past year & 249 & 42 (16.9) & $28(18.0)$ & $14(15.1)$ & n.s. $(14,39)$ \\
\hline \multirow[t]{2}{*}{ Mother } & Lifetime & 255 & $130(51.0)$ & $81(50.0)$ & $49(52.7)$ & n.s. $(34,13)$ \\
\hline & Past year & 280 & $68(24.3)$ & $36(20.5)$ & 32 (30.8) & n.s. $(9,13)$ \\
\hline \multirow[t]{2}{*}{ Spouse } & Lifetime & 42 & $10(23.8)$ & $5(22.7)$ & $5(25.0)$ & n.s. $(45,215)$ \\
\hline & Past year & 46 & 5 (10.9) & $2(7.7)$ & $3(15.0)$ & n.s. $(41,215)$ \\
\hline \multirow{2}{*}{$\begin{array}{l}\text { Older } \\
\text { brother }\end{array}$} & Lifetime & 82 & $14(17.1)$ & $13(22.8)$ & $1(4.0)$ & $0.04(40,180)$ \\
\hline & Past year & 88 & $6(6.8)$ & $6(10.0)$ & $0(0.0)$ & n.s. $(34,180)$ \\
\hline \multirow{2}{*}{$\begin{array}{l}\text { Older } \\
\text { sister }\end{array}$} & Lifetime & 77 & $14(18.2)$ & $9(18.4)$ & 5 (17.9) & n.s. $(46,179)$ \\
\hline & Past year & 85 & $5(5.9)$ & $3(5.8)$ & $2(6.1)$ & n.s. $(38,179)$ \\
\hline \multirow{2}{*}{$\begin{array}{l}\text { Younger } \\
\text { brother }\end{array}$} & Lifetime & 77 & 15 (19.5) & $9(18.4)$ & $6(21.4)$ & n.s. $(46,179)$ \\
\hline & Past year & 90 & $2(2.2)$ & $0(0.0)$ & $2(5.7)$ & n.s. $(33,179)$ \\
\hline \multirow{2}{*}{$\begin{array}{l}\text { Younger } \\
\text { sister }\end{array}$} & Lifetime & 75 & $23(30.7)$ & $15(30.6)$ & $8(30.8)$ & n.s. $(48,179)$ \\
\hline & Past year & 84 & $12(14.3)$ & $6(11.8)$ & $6(18.2)$ & n.s. $(39,179)$ \\
\hline \multirow[t]{2}{*}{ Child } & Lifetime & 23 & $0(0.0)$ & $0(0.0)$ & $0(0.0)$ & $\mathrm{n} / \mathrm{a}(44,235)$ \\
\hline & Past year & 26 & $0(0.0)$ & $0(0.0)$ & $0(0.0)$ & $\mathrm{n} / \mathrm{a}(41,235)$ \\
\hline \multirow{2}{*}{$\begin{array}{l}\text { Any family } \\
\text { member }\end{array}$} & Lifetime & 220 & 134 (60.9) & $90(63.4)$ & $44(56.4)$ & n.s. $(82, \mathrm{n} / \mathrm{a})$ \\
\hline & Past year & 243 & $66(27.2)$ & $37(24.2)$ & $29(32.2)$ & n.s. $(59, \mathrm{n} / \mathrm{a})$ \\
\hline \multirow{2}{*}{$\begin{array}{l}\text { People outside } \\
\text { the family }\end{array}$} & Lifetime & 285 & $25(8.8)$ & $19(10.8)$ & $6(5.5)$ & n.s. $(17,0)$ \\
\hline & Past year & 295 & $10(3.4)$ & $6(3.3)$ & $4(3.5)$ & n.s. $(7,0)$ \\
\hline
\end{tabular}

Missing data were excluded from the analysis

$p$ : chi-square test, Fisher's exact test

n/a: not applicable

n.s.: not significant 